\title{
Noun Phrases of Jace Wayland's Utterances in Mortal Instruments: City of Bones
}

\author{
Dimas Indra Pratama \& Arina Isti'anah \\ masdimas24@gmail.com \& arina@usd.ac.id \\ English Letters Department, Universitas Sanata Dharma
}

\begin{abstract}
A noun phrase is one of the important elements in building a sentence. Every noun phrase has its own head of the phrase. The structure of the noun phrase can be different according to the modification of the head. There are two kinds of modification to the head of the phrase: premodification and post-modification. The existence of the modifiers plays certain roles to the noun phrase. This article presents how the pre-modification affects the character in a literary work. Cassandra Clare's Mortal Instruments: City of Bones was chosen as the work to observe. Stylistic approach is used in order to conduct this study. The data of the study is collected from the noun phrases found in one of the character's utterances, Jace Wayland. The analysis presented in this article covers the types of structure, distribution, and function of noun phrases. This study found several results of the analysis. First, there are seven types of noun phrase structure found in the utterances of Jace Wayland. Second, there are four main functions of a noun phrase in a clause: subject, object, prepositional complement, and predicative complement. Third, the noun phrases also have significant role in revealing the character of Jace Wayland: being descriptive and direct.
\end{abstract}

Keywords: noun phrase, stylistics, pre-modification.

\section{Introduction}

People nowadays have several ways to entertain themselves. One of the most common ways is through literary works such as poem, short story, novel, and drama. Throughout the developments of technology, one of the literary works that is still enthused by many people is novel, a fiction novel for example. Unlike non-fiction novel, a fiction novel is a popular work because of its ability to make the readers experience the fantasy life that they cannot have in the real life situation. Barnes in Greaney states that "Novel comes out of life not theories about either life or literature" (2006:1).
In addition, a novel can be considered as a medium for many authors to enhance their writing skill. A literary work can be affected by the authors in terms of theirs style of writing. Although authors can be different from one to others, they put their work in an unusual technique in spesific words in order to achieve their purpose. A novel can also be the perfect medium source for many criticisms and interpretations of people. It is obvious that many linguistic units are found in the novel.

A novel by Cassandra Clare entitled Mortal Instruments: City of Bones tells us about an alternative world of demon hunters to battle the evil on that world. Clare uses some of the linguistic features in order to 
enhance the atmosphere or the situation in the novel. For example is the noun phrases found in the structure of the sentences used in the story. The descriptions of the characters are also influenced by the existence of noun phrase. Jace Wayland is one of the characters shown in the story of the novel. The conversation of the characters can also provide many noun phrases to be found such as in Jace Wayland's utterances troughout the story. The author of the story writes the spesific noun phrase to indicate some information related to the characters and the story of the novel.

Studies on noun phrase have attracted some scholars. Pratama (2012) observed noun phrase in Edgar Allan Poe's "The Purloined Letter". He found that the use of post-modification of the noun phrase was used by the author to avoid overwriting for the limited space in fulfilling the condition of the short story writing rules. Yudit (2005) identified how the noun phrases reveal Hemingway's style from his works. Yudit identified the noun phrases from two of the famous author's works, Ernest Hemmingway, short stories "Hills like White Elephants" and "Indian Camp". The research concluded that the characters of Hemmingway's style are simplicity, directness, and emotional understatement.

\section{Review of Noun Phrase}

Noun phrase comes in different forms and structures depending on its function in a sentence. Every noun phrase has the head that is modified and the central element in the phrase. Looking at structure of the noun phrase, it is distinguished into two kinds of noun phrase: simple (e.g. jewel, corn, and trouble) and complex noun phrase (e.g. the colorful balloon). According to Maestre (1998: 3) the term simple is used because of the head of noun phrase is not modified by other phrases, whereas the term complex is used because the head is modified by other phrases as the pre-modifiers and postmodifiers. This study also applies the theory of noun phrase constituents proposed by Quirk, Greenbaum, Leech, and Svartvik. Noun phrase constituents are distinguished into determiner, pre-modifier, head, and post-modifier.

Those noun phrases also have distinctive properties as in the function in a clause or sentences. Huddleston and Pullum (2005: 82) propose that the main functions of noun phrases can occur are in the following.

\section{In Clause Structure}

The first function of noun phrase to occur in a clause is as a subject. Typically, the subject of a clause is a noun phrase. The other form of subject in a clause is subordinate clause. For example, in a clause a student helped us, noun phrase a student is the subject of the clause since the basic position of a subject is before the verb helped.

Almost all of the object of a clause is in the form of noun phrase. In order to identify the object of a clause, there are some indications of the object's characteristics. An object must be licensed by a verb since it is a special form of complement in the verb phrase. Sometimes the existence of an object is obligatory to certain verbs.

Predicative complement is the next kind of the verb dependent and commonly in form of noun phrases. It contrasts the direct object. For example:

(1) She is a student.

(2) She found a good speaker.

From the example (1) the noun phrase $a$ student is a predicative complement because the noun phrase denotes a feature that is ascribed to the subject she. On the other hand, the noun phrase a good speaker in example (2) is a direct object since it refers to participants in the situation. However, a predicative complement does not refer to the participants in the situation like the direct object does. 


\section{In Prepositional Structure}

In order to be a preposition, a word has to have a complement in the form of noun phrase. It means that noun phrase has the function to complement the preposition to form a prepositional phrase structure. In a clause, we were talking to a student, a phrase to a student is a prepositional phrase. It is indicated by the preposition to followed by the noun phrase $a$ student.

Noun phrases are not limited to complete the clause and prepositional structure only. They can also fill the structure of adverbial adjunct, object complement, and appositive. The examples of each kind are as follow.

\section{(1) We saw her several times.}

The noun phrase several times is adverbial adjunct because it modifies the entire clause by providing additional information about the time.

(2) Our cousins always called my uncle $a$ dictator.

The noun phrase a dictator is an object complement because it follows directly the direct object. It is different from indirect object because object complement describes the direct object not the other participant of the verb just like the indirect object.

(3) Our friend, the mayor, lives here.

The noun phrase the mayor is the appositive because it renames or describes the noun right beside it.

In order to conduct the analysis, this study uses the stylistic approach. The approach gives the attention of the scientific study of the language and its structure in order to show how the linguistic features contribute to the meaning and influence of a literary work. According to Simpson, doing stylistics is like exploring a language and spesifically exploring the creativity in using the language (2004: 3).

\section{The Types of Noun Phrases}

The types of noun phrases found in Jace Wayland's utterances are found in 7 distinctive types of structure based on the parts of the noun phrases such as the determiners, pre-modifiers and postmodifiers. Each of the structure has its own occurrence in some parts of utterances throughout the novel. Based on the finding of analysis, the types of noun phrase in the utterances are shown in table 1 bellow.

Table 1. The Types of Noun Phrases in Jace Wayland's Utterances

\begin{tabular}{|l|l|c|c|}
\hline No. & \multicolumn{1}{|c|}{ Structure } & Number & Percentage \\
\hline 1. & Determiner + Head & 339 & $48.9 \%$ \\
\hline 2. & Determiner + Pre-modifier + Head & 117 & $16.9 \%$ \\
\hline 3. & Pre-modifier + Head & 86 & $12.4 \%$ \\
\hline 4. & Determiner + Head + Post-modifier & 76 & $11 \%$ \\
\hline 5. & Head + Post-Modifier & 38 & $5.5 \%$ \\
\hline 6. & Determiner + Pre-modifier + Head + Post-modifier & 26 & $3.8 \%$ \\
\hline 7. & Pre-modifier + Head + Post-modifier & 11 & $1.6 \%$ \\
\hline \multicolumn{2}{r|}{ Total } & $\mathbf{6 9 3}$ & $\mathbf{1 0 0 \%}$ \\
\hline
\end{tabular}

Table 1 shows that there are several different structures of noun phrases found in Jace Wayland's utterances. From the data collected in the analysis, there is a total number of 693 noun phrases found in the utterances. Each of the structure has different percentages of occurrence in the utterances throughout the novel. The table also shows that are three dominant structures with the most significant percentage such as determiner + head, determiner + pre-modifier + head, and premodifier + head. 
(4) $\frac{\text { His }}{\text { Poss }}+\frac{\text { poetry }}{\mathrm{H}}$

The word his, my, and your are categorized as the possessive determiner along with the other form such as her, its, their, our, and inflected 's possessive form. Noun phrase (6) shows that the word his is the determiner to the noun phrase head poetry.

$$
\text { (5) } \frac{A n}{\mathrm{I} \text { art }}+\frac{\text { electric }}{\mathrm{Adj}}+\frac{\text { eel }}{\mathrm{H}}
$$

Noun phrase (7) shows that the indefinite article an is the determiner to modify the noun phrase head eel which is singular count noun. This time the noun phrase has another property to modify the head. After determiner, there is pre-modifier to modify the noun phrase head. In noun phrase (7) the adjective electric functions as the pre-modifier of the phrase.

(6) $\frac{\text { Foreign }}{\text { Adj }}+\frac{\text { diplomats }}{\mathrm{H}}$

The word his, my, and your are categorized as the possessive determiner along with the other form such as her, its, their, our, and inflected 's possessive form. Noun phrase (6) shows that the word his is the determiner to the noun phrase head poetry.

$$
\text { (7) } \frac{A n}{\mathrm{I} \text { art }}+\frac{\text { electric }}{\mathrm{Adj}}+\frac{\text { eel }}{\mathrm{H}}
$$

Noun phrase (7) shows that the indefinite article an is the determiner to modify the noun phrase head eel which is singular count noun. This time the noun phrase has another property to modify the head. After determiner, there is pre-modifier to modify the noun phrase head. In noun phrase (7) the adjective electric functions as the pre-modifier of the phrase.

(8) $\frac{\text { Foreign }}{\text { Adj }}+\frac{\text { diplomats }}{\mathrm{H}}$

Noun phrase (8) only contains of premodifier and the head. The adjective foreign modifies the noun phrase head diplomats which is in the plural form of noun. For a pre-modifier and head structure, this type of structure commonly occurs with the adjectives or nouns as in noun phrase (8) as the pre-modifier.

\section{The Distribution of Noun Phrases}

To begin with, Huddleston and Pullum (2005: 82) mention that based on the function, there are four main functions of noun phrases namely subject, object, predicative complement, and prepositional complement. In order to point out the distribution of the noun phrase, this analysis presents the percentage in terms of the number of occurrence. The data collected in the previous analysis is based on the order of appearance.

Applying the theory of Huddlestone and Pullum, there are seven kinds of noun phrase function in a clause found according to noun phrase data of Jace Wayland's utterances. The table 2 below explains the distribution of the noun phrases based on their functions in a clause.

Table 2. The Distribution of Noun Phrases in the Utterances

\begin{tabular}{|c|l|c|c|}
\hline No. & \multicolumn{1}{|c|}{ Functions in a Clause } & Number & Percentage \\
\hline 1. & Object & 213 & $30.7 \%$ \\
\hline 2. & Prepositional Complement & 187 & $27 \%$ \\
\hline 3. & Predicative Complement & 165 & $23.8 \%$ \\
\hline 4. & Subject & 119 & $17.2 \%$ \\
\hline 5. & Adverbial Adjunct & 5 & $0.7 \%$ \\
\hline 6. & Object Complement & 2 & $0.3 \%$ \\
\hline 7. & Appositive & 2 & $0.3 \%$ \\
\hline \multicolumn{2}{|c|}{ Total } & $\mathbf{6 9 3}$ & $100 \%$ \\
\hline \multicolumn{2}{|c|}{} \\
\hline
\end{tabular}


Table 2 above shows that there are four main functions of noun phrases dominating the data of occurrence. There are also three other functions found in the analysis such as adverbial adjunct, object complement, and appositive. The following parts present the examples and discussion about the four dominant noun phrase functions.

(9) No mundane doctor would know how to heal those wounds.

The phrase in italic shown in clause (9) is a noun phrase with the function as a direct object in a clause. The two clause shows that the noun phrase those wounds have the structure of determiner followed by the head of the phrase. There are 97 noun phrases with this type of structure functioning as a direct object found in the utterances of Jace Wayland.

(10) They're runes, burned into our skin.

The noun phrase our skin in clause (10) is a prepositional complement of the preposition into. The noun phrase itself has the structure of determiner followed by the head of the phrase. The word our is the determiner of the singular noun head phrase skin. There are 97 noun phrases sharing this similar structure of noun phrase which function as prepositional complement.

\section{(11) That's your problem.}

Clause (11) shows that the italic phrases is the noun phrase functioning as predicative complement because it follows the linking verb is. The structure of the noun phrase consists of determiner and the head of the phrase. Obviously, this is the most noun phrase structure type to occur as predicative complement with total number of 77 noun phrases found from the data collected. In clause (11), the possessive determiner your modify the singular noun head phrase problem.

(12) The meek may inherit the earth.
Clause (12) shows that the noun phrase the meek is the subject of the clause. The structure of the phrase is determiner followed by the head of the phrase. The determiner of the phrase is indicated by the definite article the in the initial position of the phrase. The noun word meek is the head of the phrase. According to the data, there are 64 noun phrases found having this kind of structure and functioning as the subject of the clause.

\section{Noun Phrases Revealing Jace Wayland's Character}

The noun phrases found in the utterances of Jace Wayland are various in terms of the structure. Distinctive structure of certain noun phrases can add more information to the head of the noun phrase also. Therefore, the simplicity and complexity of the noun phrase construction play a role to the function of the noun phrases to Jace Wayland's character. All the occurring noun phrase in the utterances found in the analysis will reveal the character of Jace Wayland. Below are the examples of the characteristic of Jace Wayland revealed by the occurrence of noun phrase.

\section{Jace Wayland's Descriptive Character}

There are two kinds of noun phrase, one with simple structure and one with complex structure. The use of each kind will reveal different function. The simple noun phrases are those without any modification of the head of the phrase. On the other hand, complex noun phrase has several modifications to the head of the phrase by pre-modifier and post-modifier. According to the data collected, almost half of the noun phrase data from Jace Wayland utterances is constructed with complex noun phrase structure. There are 354 noun phrases with the modification of pre-modifier and post modifier from the total of 693 noun phrases found in the utterances. The main function of the modification of the head phrase is to give additional information to the phrase and 
also restrict the things that are mentioned making them specific. The modification by pre-modifier and post modifier in the complex noun phrases will reveal the characteristic of Jace Wayland being descriptive character.

The pre-modification and postmodification to the noun phrase head are used by Jace Wayland in his utterances when he wants to describe certain things such as a thing, place, and person. The examples of the complex noun phrases used by Jace Wayland in the utterances according to the use of the phrase are as follows.

\section{a. To Describe a Thing}

In order to describe something, most of the times Jace Wayland uses the complex form of noun phrase. Because noun phrase's head is a noun, it is usually used to describe a thing that is common or even special in an utterances. according to the data almost all of the noun phrases describing a thing have the function as direct object. Below is the example of the noun phrase.

(13) When I found her, she was lying on the floor in a pool of blood with a dying demon practically on top of her.

Noun phrase in clause (13) has the structure of determiner, head, and postmodifier. It shows that when Jace wants to describe something, he adds some more additional information. The post-modifier of noun phrase in clause (13) is prepositional phrase. In fact, there are several prepositional phrase that is used in the noun phrase. The preposition of, with, and on are the indicators of each kind of prepositional phrase. It means that Jace does not just stop explaining a pool of blood but also he gives more information with other prepositional phrase such with a dying demon and on top of her in order to describe the pool of blood more detailed.

\section{b. To Describe a Place}

Jace Wayland also used noun phrases to describe a place he wants to point to the other characters. Because the pupose is to describe a place, this kind of noun phrase is usually found following prepositions in prepositional phrases. The example of the noun phrase is as follows.

(14) There are probably other living worlds like ours.

Noun phrase in clause (14) shows that Jace Wayland uses complex noun phrase in order to describe a place such as a world. There are adjective word other and present participle living as the pre-modifier of the head phrase world. In addition, the prepositional phrase like ours as the postmodifier modifies the head phrase. The modifications of the noun head give additional information like in noun phrase of clause (14). The word other and living specifies the noun head world meaning that there are other worlds that is living. The prepositional phrase like ours also specifies the noun head because it restricts the noun head.

\section{c. To Describe a Person}

This is the last function of the complex noun phrase that is used by Jace Wayland in his utterances. Noun phrases are used to describe a person for example the looks, characteristics, and all the things connected to the person mentioned. This kind of noun phrase is usually found with the function of subject and direct object in a clause. Following is the example of the noun phrase used to describe a person.

(15) The two men who claimed they were emissaries of Valentine referred to him as Lucian Graymark.

The noun phrase in clause (15) is used to describe a person. It has the structure of determiner, head, and post-modifier. The head of the phrase is the plural noun men. The cardinal number two gives the additional number of quantity of the head phrase. The finite clause who claimed they were emissaries of Valentine also describes the noun head without having to make 
another clause in order to specify the noun head.

\section{Jace Wayland's Direct Character}

When people are direct, it means that they are being straightforward for anything they do or say. Some of the noun phrases in the utterances of Jace Wayland is used when he is being direct to the other character. The structure of the noun phrase used in Jace Wayland's character in order to describe his character is various. Most of the time the structure that is used in the utterances are those with simple structure of noun phrase. According to the data, there are 339 simple noun phrases foun in the utterances used by Jace Wayland. The noun phrases are also used in every function of the clause possible such as subject, object, or complements. The examples of the noun phrase used by Jace Wayland that reveal his character of being direct are as follows.

\section{(16) "Valentine is in the ground."}

In the utterance (83), the phrase the ground is a noun phrase functioning as prepositional complement. It has the structure of determiner the and the head of the phrase ground. The noun phrase the ground is used by Jace Wayland in his utterances to describe about the whereabouts of the character Valentine. He means to say that Valentine is dead but instead he says that Valentine is literally in the ground as where the dead people are in, buried in the ground.

"Your Simon is one of the most mundanes I've ever encountered."

The phrase your Simon in utterance (17) is a noun phrase functioning as the subject of the clause. It has the structure of determiner and the head of the phrase. The possessive word your is the determiner of the proper noun head Simon. The phrase your Simon is used by Jace Wayland in his utterance to convey the idea that Simon, a name of a character in a book, has the characteristic of a possession. That is why Jace put the possessive determiner before the name because that is unusual in terms of politeness.

\section{(18) "You're a bigger idiot than you look."}

In utterance (18), the noun phrase a bigger idiot is a predicative complement. It is constructed by determiner, adjective, and the head of the phrase. The indefinite article $a$ is the determiner of the phrase. The adjective word bigger is the pre-modifier of the noun head idiot. The noun phrase is used by Jace Wayland to address other character in an unpleasant way.

\section{Conclusion}

According to the analysis, the noun phrases found in the utterances of Jace Wayland are distinguished into 7 types of structure. Each of the structure has the significance in terms of occurrence. The structure types can be classified into: (1) Determiner + Head, (2) Determiner + Premodifier + Head, (3) Pre-modifier + Head, (4) Determiner + Head + Post-modifier, (5) Head + Post-modifier, (6) Determiner + Premodifier + Head + Post-modifier, (7) Premodifier + Head + Post-modifier.

The second analysis identifies the distribution of the noun phrases in terms of their function in a clause. According to the data collected, the noun phrases found in the utterances has the main function such as the object, prepositional complement, predicative complement, subject, and other function such as adverbial adjunct, object complement, and appositive in a clause.

The use of noun phrase in utterances can also have significant function especially to the character of the person who uses the noun phrase. In the third analysis, the noun phrases have significance over Jace Wayland's character such as descriptive and direct. The noun phrases are used by Jace to describe things, person, and place. They are also used to make direct utterances by Jace Wayland.

In short, the elements and functions of noun phrases can have a special role in 
utterances. They can be distinguished into several types with modification to the head of the phrase to give additional information. Noun phrases also can have different function in a clause with their significant function the character of a person.

\section{References}

Clare, Cassandra. Mortal Instruments: City of Bones. London: Margaret K. Mc. Elderry, 2007.

Greaney, Michael. Contemporary Fiction and the Uses of Theory. New York: Palgrave Macmilan, 2006.

Huddleston, Rodney and Geoffrey K. Pullum. A Student's Intoduction to English Grammar. Cambridge: Cambridge University Press, 2005.

Maestre, Maria Dolorez Lòpez. "Noun Phrase "Complexity" as a Style Marker: An Exercise in Stylistic Analysis." Atlantis. Vol. 20. No. 2 (1998): p. 91-105. Jstor. (www.jstor.org/stable/41055516) September 26, 2016.

Simpson, Paul. Stylistics: A Resource Book for Students. London: Routledge, 2004.

Quirk, Randolph and Sidney Greenbaum. A University Grammar of English. Essex: Longman Group Ltd., 1985.

Yudit. "The Noun Phrases Revealing Hemingway's Style: A Stylistic Approach." Phenomena. Vol. 9. No. 2. (2005): p. 125. Universitas Sanata Dharma. 